Indonesian Journal of Counseling and Development p-ISSN: 2685-7375 | e-ISSN: 2685-7367

Vol. 01, No. 02, Desember 2019, pp. 75-83

\title{
Pemanfaatan Layanan Bimbingan dan Konseling dalam Pengoptimalan Keterampilan Mengingat Mahasiswa
}

\author{
Romi Fajar Tanjung \\ Institut Agama Islam Negeri (LAIN) Batusangkar \\ e-mail: romifajarr@gmail.com
}

\begin{abstract}
Skills are skills that need to be controlled so that any work or tasks that can be completed and achieve maximum results. A student needs to master many skills learned. One of the skills learned are skills of memory. Skills is very important considering ruled that any information received can be processed, stored and can be used when the information is needed. This study aims to identify the skills of memory students and analyze the utilization of counseling services in the optimization of skills given the student. The population of this research is student counseling Universitas Negeri Padang (UNP). The research sample is student counseling Universitas Negeri Padang (UNP) as many as 84 people. The sampling technique using simple random sampling. Collecting data using questionnaire instrument learning skills (memory). Data were analyzed using percentages with the help of Microsoft Exel. The research found that the skills of memory counseling students have not developed optimally. Thus, students need to seek out and study methods or techniques memory is good, so that any information received can be processed, stored and reused when the information is needed. The research found that the skills of memory counseling students have not developed optimally. Thus, students need to seek out and study methods or techniques memory is good, so that any information received can be processed, stored and reused when the information is needed. The research found that the skills of memory counseling students have not developed optimally. Thus, students need to seek out and study methods or techniques memory is good, so that any information received can be processed, stored and reused when the information is needed. Guidance and counseling to facilitate the students in considering the optimization skills of memory.
\end{abstract}

Keywords: Guidance and counseling, skills of memory, students

\begin{abstract}
Abstrak. Keterampilan merupakan keahlian yang perlu dikuasai agar setiap pekerjaan atau tugas yang dikerjakan dapat diselesaikan dan mencapai hasil yang maksimal. Seorang mahasiswa perlu menguasai berbagai keterampilan belajar. Salah satu keterampilan belajar yaitu keterampilan mengingat (memory). Keterampilan mengingat sangat penting dikuasai supaya setiap informasi yang diterima dapat diproses, disimpan serta dapat digunakan ketika informasi tersebut dibutuhkan. Penelitian ini bertujuan mengidentifikasi keterampilan mengingat (memory) mahasiswa dan menganalisis pemanfaatan layanan bimbingan dan konseling dalam pengoptimalan keterampilan mengingat mahasiswa. Populasi penelitian ini yaitu mahasiswa bimbingan konseling Universitas Negeri Padang (UNP). Sampel penelitian merupakan mahasiswa bimbingan konseling Universitas Negeri Padang (UNP) sebanyak 84 orang. Teknik pengambilan sampel menggunakan simple random sampling. Pengumpulan data menggunakan instrumen angket keterampilan belajar (mengingat). Teknik analisis data menggunakan persentase dengan bantuan microsoft exel. Hasil penelitian ditemukan bahwa keterampilan mengingat (memory) mahasiswa bimbingan konseling belum berkembang secara optimal. Mahasiswa perlu mencari tahu dan mempelajari metode atau teknik mengingat (memory) yang baik, supaya setiap informasi yang diterima dapat diproses, disimpan dan digunakan kembali ketika informasi tersebut dibutuhkan. Pelayanan bimbingan dan konseling dapat menfasilitasi mahasiswa dalam pengoptimalan keterampilan mengingat (memory).
\end{abstract}

Kata kunci: Bimbingan dan konseling, keterampilan mengingat, mahasiswa 


\section{PENDAHULUAN}

Mahasiswa di perguruan tinggi menjadi objek dan subjek. Ditinjau dari sisi objek mahasiswa merupakan fokus dalam pelaksanaan kegiatan pendidikan yang telah didesain dengan sistematis serta bersifat ilmiah sehingga terwujudnya proses pembelajaran. Ditinjau dari sisi subjek mahasiswa dituntut untuk dapat menguasai standar kompetensi yang telah ditentukan oleh Kemenristekdikti dalam bentuk peraturan dalam penyelenggaraan perguruan tinggi, kompetensi yang perlu dikuasai oleh mahasiswa meliputi kompetensi akademik, pribadi, sosial, profesional dan spritual (El Fiah, 2004).

Kompetensi tersebut dapat berkembang dengan baik melalui proses latihan dan penguasaan keterampilan. Terutama dalam menghadapi era revolusi industri 4.0, mahasiswa dituntut untuk selalu mengupgrade keterampilannya (Tanjung, 2019). Dalam proses pembelajaran di perguruan tinggi kita selalu diberikan berbagai informasi yang berkaitan dengan keilmuan mahasiswa, sehingga mahasiswa dituntut untuk menyimpan serta menguasai informasi yang disampaikan tersebut. oleh sebab itu, dalam hal menyimpan dengan baik segala informasi yang didapat, maka mahasiswa perlu keterampilan mengingat. Mahasiswa yang memiliki keterampilan mengingat akan memiliki teknik dan metode yang baik dalam menerima informasi, menyimpan dan memanggil kembali informasi tersebut dengan mudah ketika dibutuhkan.

Tidak ada sesuatupun yang dapat dipelajari tanpa memasukkannya ke dalam komponen ingatan. Ingatan merupakan hasil rekaman dalam otak manusia mengenai pengalaman masa yang lampau dan pengetahuan yang telah dipelajari baik secara disadari maupun tidak disadari (Gie, 2006). Ingatan merupakan kemampuan jiwa untuk memasukkan (learning), menyimpan (retention), dan menimbulkan kembali (remembering) hal-hal yang telah lampau. Tanpa kolaborasi fungsi ingatan yang diperlukan, kita tidak dapat belajar (Djamarah, 2011).

Guru yang menjelaskan langkah-langkah terjadinya fotosintesis mungkin dapat dimengerti dengan baik oleh seorang murid kelas lima, namun jika anak tersebut tidak mampu menyimpan informasi tersebut, pelajaran itupun tidak ada artinya (Levine, 2002). Seseorang yang kemampuan ingatannya rendah belum tentu kemampuan intelektualnya rendah, hanya saja ia mengalami gangguan dalam sistem penyimpanan informasi (Levine, 2002).

Beberapa hal yang dapat dilakukan supaya informasi yang didapatkan tersimpan untuk jangka waktu lebih lama dalam ingatan jangka pendek. Levine (2002) mengemukakan caranya dengan mengucapkannya (a) dalam hati, (b) membuat gambaran dalam kepala, (c) kalau berupa data visual bisa kita wujudkan dalam kata-kata, sehingga input baru menetap lebih lama dalam 
ingatan jangka pendek. Strategi tersebut dikenal sebagai strategi menghafal dan sangat berguna bagi pelajar.

Informasi baru yang diterima, agar dapat menetap lebih lama pada ingatan jangka pendek dapat dilakukan dengan Recoding. Recoding biasanya dapat dilakukan dengan cara parafrase yaitu metode yang digunakan untuk mempersingkat kalimat panjang (Levine, 2002). Kemudian mendengarkan dengan baik, sangat membantu dalam mengingat sesuatu. Ingatan ini dibagi dua, ingatan yang berfungsi aktif dan tidak berfungsi aktif. Ingatan berfungsi aktif merupakan tempat dimana berbagai tujuan atau komponen suatu aktivitas dapat dipertahankan sekian lama hingga aktivitas tersebut selesai dilakukan (Levine, 2002).

Kemudian ada yang disebut dengan ingatan jangka panjang dimana informasi atau input di simpan secara sistematis di dalam penyimpanan data serta dapat diakses kembali ketika dibutuhkan. Hal-hal di atas juga dapat dipergunakan supaya informasi yang diterima tersimpan baik di ingatan jangka panjang. Penyimpanan data merupakan tindakan yang sistematis dalam memasukkan informasi ke dalam otak atau sistem penyimpanan ingatan jangka panjang, sementara akses merupakan proses yang kita lalui untuk menemukan lokasi informasi yang telah tersimpan dalam penyimpanan ingatan (Levine, 2002).

Tantangan terbesar bagi ingatan jangka panjang adalah menyimpan informasi secara sistematis, meletakkannya di suatu tempat yang nantinya dapat kita temukan kembali. Tindakan penyimpanan materi untuk penggunaan di masa mendatang disebut konsolidasi. Empat konsolidasi tersebut yaitu informasi dapat disimpan sebagai pasangan (nama dengan wajah), sebagai prosedur (bagaimana cara mengikat dasi), sebagai kategori (jenis-jenis buah jeruk), atau sebagai aturan atau pola tertentu (dimana tanda tanya mesti diletakkan dalam suatu kalimat) (Levine, 2002).

Keterampilan mengingat merupakan salah satu keterampilan belajar yang sangat penting dikuasai. Tingginya tingkat keterampilan belajar mahasiswa akan memberikan dampak positif terhadap hasil studi mahasiswa (Tanjung, Neviyarni, Firman, 2018a). Peningkatan keterampilan mengingat dapat ditingkatkan dengan berbagai cara, salahsatunya melalui pelayanan bimbingan dan konseling.

Pelayanan bimbingan dan konseling merupakan salah satu kegiatan yang memberikan pelayanan profesional dan saat ini lebih terfokus kepada dunia pendidikan, dari tingkat pendidikan SD, SLTP, SLTA terutama perguruan tinggi. Bimbingan dan konseling di perguruan tinggi merupakan proses pemberian bantuan kepada mahasiswa yang dilakukan secara berkesinambungan agar mahasiswa tersebut dapat memahami dirinya, sehingga ia sanggup mengarahkan dirinya sesuai dengan tuntutan dan keadaan lingkungan kampus, keluarga, dan masyarakat (El Fiah, 2014). 
Konselor merupakan pihak yang membantu klien/peserta layanan bimbingan dan konseling. Konselor dalam menjalankan perannya bertindak sebagai fasilitator, penasihat, guru dan konsultan yang mendampingi klien sampai klien dapat menemukan dan mengatasi masalah yang dihadapinya (Lubis, 2011). Seorang konselor harus memiliki karakteristik yang baik, serta melakukan layanan bimbingan dan konseling berbasis penelitian untuk pengembangan profesi BK kedepannya (Ardimen, 2016).

Konselor dalam melaksanakan pelayanan bimbingan dan konseling membantu klien untuk mencegah kondisi negatif berkembang, mengembangkan potensi, pengentasan permasalahan serta pemeliharan kondisi positif agar kehidupan klien menjadi efektif (Gibson, \& Mitchel, 2008). Dengan pelayanan bimbingan dan konseling yang dilaksanakan, diharapkan mahasiswa menguasai suatu keterampilan sehingga memunculkan suatu sikap dan perilaku yang mengarah kepada hal-hal positif (Schwitzer, 2002; Lee et al, 2009), seperti mahasiswa mencari tahu teknik atau metode mengingat yang baik, memahami, dan menerapkan dalam kehidupan sehari-hari terutama saat menjalani studi di perguruan tinggi.

\section{METODOLOGI}

Penelitian ini menggunakan pendekatan kuantitatif dengan jenis penelitian yaitu deskriptif kuantitatif. Populasi penelitian merupakan mahasiswa bimbingan dan konseling Universitas Negeri Padang (UNP). Sampel penelitian sebanyak 84 orang mahasiswa. Teknik pengambilan sampel menggunakan simple random sampling. Pengumpulan data menggunakan instrumen angket keterampilan belajar (mengingat). Angket yang digunakan yaitu jenis skala likert dengan menggunakan lima pilihan jawaban; Sangat Sesuai, Sesuai, Cukup Sesuai, Tidak Sesuai, Sangat Tidak Sesuai, dengan rentang skor 1-5. Kemudian data yang diperoleh dari pengadministrasian instrumen akan diolah dan dianalisis menggunakan microsoft exel dan dideskripsikan dalam bentuk frekuensi, persentase dan grafik. Setelah itu, temuan penelitian dianalisis dengan teori dan hasil-hasil penelitian yang relevan dengan penelitian ini. Berikut akan diuraikan pernyataan item angket keterampilan belajar (mengingat).

Pernyataan Keterampilan Mengingat

No

Saya mempelajari kembali materi perkuliahan di rumah agar dapat diingat 


\begin{tabular}{cl}
\hline 2 & $\begin{array}{l}\text { Saya berdiskusi dengan teman untuk memudahkan mengingat materi perkuliahan yang baru saja } \\
\text { dibahas }\end{array}$ \\
\hline 3 & $\begin{array}{l}\text { Saya membuat kesimpulan sendiri untuk memudahkan mengingat materi perkuliahan tanpa mengubah } \\
\text { makna kalimat tersebut }\end{array}$ \\
\hline 4 & $\begin{array}{l}\text { Saya membaca materi perkuliahan dengan nyaring ketika sendirian untuk mempermudah dalam } \\
\text { mengingat }\end{array}$ \\
\hline 5 & $\begin{array}{l}\text { Saya membuat catatan saku (di HP atau Buku) untuk memudahkan dalam mengingat materi } \\
\text { perkuliahan }\end{array}$ \\
\hline 6 & Saya memberi warna kalimat yang penting untuk memudahkan dalam mengingat materi perkuliahan \\
\hline
\end{tabular}

\section{HASIL DAN DISKUSI}

Data penelitian dikumpulkan menggunakan instrumen keterampilan belajar (mengingat), berikut diuraikan gambaran data penelitian yang diperoleh.

Tabel 1. Tabulasi Data Keterampilan Mengingat Mahasiswa

\begin{tabular}{|c|c|c|c|c|c|c|c|c|c|c|c|c|}
\hline \multirow{2}{*}{ Kategori Pilihan } & \multicolumn{2}{|c|}{ Item 1} & \multicolumn{2}{|c|}{ Item 2} & \multicolumn{2}{|c|}{ Item 3} & \multicolumn{2}{|c|}{ Item 4} & \multicolumn{2}{|c|}{ Item 5} & \multicolumn{2}{|c|}{ Item 6} \\
\hline & $\mathrm{f}$ & $\%$ & $\mathrm{f}$ & $\%$ & $\mathrm{~F}$ & $\%$ & $\mathrm{f}$ & $\%$ & $\mathrm{f}$ & $\%$ & $\mathrm{f}$ & $\%$ \\
\hline Sangat Sesuai & 6 & 7,1 & 16 & 19 & 17 & 20 & 12 & 14 & 6 & 7,1 & 18 & 21 \\
\hline Sesuai & 25 & 30 & 37 & 44 & 45 & 54 & 28 & 33 & 18 & 21 & 31 & 37 \\
\hline Cukup Sesuai & 41 & 49 & 26 & 31 & 17 & 20 & 23 & 27 & 33 & 39 & 21 & 25 \\
\hline Tidak Sesuai & 10 & 12 & 5 & 6 & 5 & 6 & 14 & 17 & 20 & 24 & 9 & 11 \\
\hline Sangat Tidak Sesuai & 2 & 2,4 & 0 & 0 & 0 & 0 & 7 & 8,3 & 7 & 8,3 & 5 & 6 \\
\hline Total & 84 & 100 & 84 & 100 & 84 & 100 & 84 & 100 & 84 & 100 & 84 & 100 \\
\hline
\end{tabular}

Tabel 1 di atas menjelaskan bahwa rata-rata 41 orang mahasiswa belum memiliki keterampilan mengingat yang optimal pada tiap-tiap aspek item yang diukur. Perguruan tinggi merupakan salah satu tempat untuk mendapatkan pendidikan dimana pendidikan tersebut bertujuan mewujudkan terkuasainya berbagai keterampilan. Pendidikan merupakan upaya mewujudkan kesejatian manusia untuk terpenuhinya harkat dan martabat kemanusiaannya melalui pengembangan pancadaya manusia tersebut (Prayitno, 2015).

Fenomena di lapangan ditemukan, mahasiswa yang telah menyelesaikan studi tetapi bingung ingin bekerja apa dan kurang percaya diri untuk memulai suatu pekerjaan, hal ini disebabkan salah satunya karena minimnya keterampilan yang dimiliki ketika telah menyelesaikan studi di perguruan tinggi. Terkadang keterampilan yang dimiliki setelah penyelesaian studi tidak jauh berbeda dengan keterampilan yang telah dimiliki ketika berada pada jenjang sekolah menengah (tidak ada peningkatan keterampilan). Kebiasaan dan perilaku yang tidak produktif selama proses studi akan berakibat terhadap penurunan kinerja (Choi et al, 2010; Hartley, 2011), selain itu, mahasiswa juga tidak akan mengalami peningkatan keterampilan apapun akibat menjalani proses yang salah selama masa studi di perguruan tinggi. Peningkatan keterampilan, seperti keterampilan mengingat (memory), hal itu dapat dikuasai apabila mahasiswa menguasai teknik atau metode mengingat dengan baik, dan hal itu dapat tercapai dengan latihan yang berkesinambungan. 


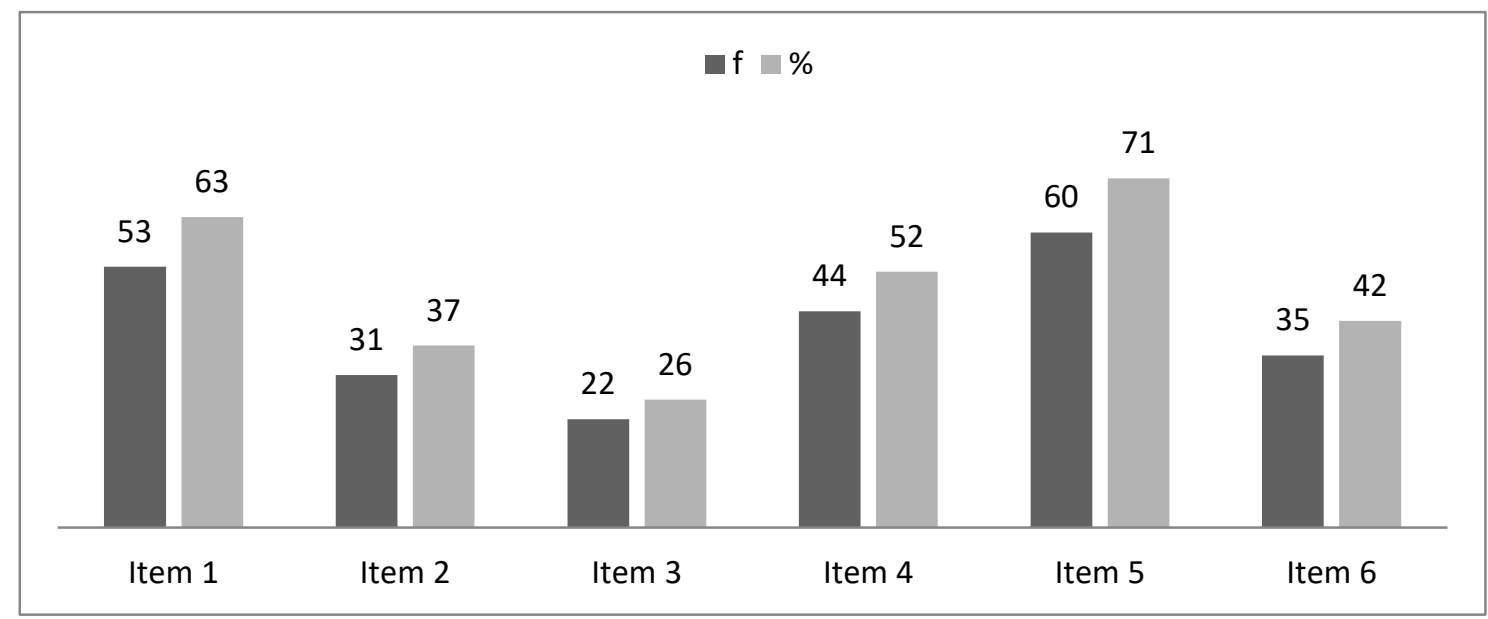

Grafik 1. Gambaran Keterampilan Mengingat Mahasiswa yang Belum Optimal

Grafik 1 di atas menunjukkan frekuensi dan persentase mahasiswa yang memberikan pilihan jawaban di bawah kategori Sesuai, artinya pilihan jawaban mahasiswa antara (Cukup Sesuai, Tidak Sesuai dan Sangat Tidak Sesuai). Berikut uraian urutan item yang susah untuk disetujui (sesuai/sangat sesuai) oleh mahasiswa, dimulai dari frekuensi terbanyak, yaitu item 5 yaitu sebanyak $71 \%$ mahasiswa, item 1 sebanyak 63\%, item 4 sebanyak 52\%, item 6 sebanyak 42\%, item 2 sebanyak $37 \%$ dan item 3 sebanyak 26\%. Dengan demikian, sebagian besar mahasiswa belum terampil dalam melakukan hal yang berkaitan dengan item 5, artinya sebagian besar mahasiswa tidak membuat catatan saku untuk memudahkan dalam mengingat materi perkuliahan.

Keterampilan mengingat (memory) merupakan keterampilan yang penting bagi mahasiswa untuk mengingat materi-materi yang dipelajari ketika berada di perguruan tinggi. Hasil studi ditemukan bahwa proses mengingat sesuatu, dimana memori bekerja memanipulasi informasi yang diterima terlebih dahulu sehingga informasi yang diperoleh tersimpan di long term memory, sedangkan short term memory biasanya terjadi penarikan langsung terhadap informasi yang diterima sebelum menggunakan atau terjadi manipulasi informasi tersebut sehingga informasi tidak tersimpan secara permanen (Brown, Neath, \& Chater, 2007; Diamond, 2013; Davelaar, Goshen-Gottstein, Haarmann, \& Usher, 2005). Oleh sebab itu, metode atau teknik dalam mengingat perlu dipelajari dan dikuasai agar informasi-informasi yang didapatkan dapat disimpan secara permanen dan dapat digunakan setiap dibutuhkan.

Pelayanan bimbingan dan konseling merupakan pelayanan bantuan profesional yang dilakukan oleh seorang guru BK/Konselor terhadap individu baik secara perorangan atau kelompok yang disebut dengan klien, dimana pelayanan yang dilakukan bertujuan untuk memandirikan kehidupan klien melalui proses pembelajaran (Prayitno \& Amti, 2009; Sukardi, 2002). Pelayanan bimbingan dan konseling efektif dalam meningkatkan salah satu keterampilan 
belajar yaitu keterampilan membaca (Tanjung, Neviyarni, Firman, 2018b), mengembangkan pola kehidupan yang efektif (Prayitno, 2001; Tohirin, 2007).

Proses belajar di perguruan tinggi memiliki beberapa karakteristik yang berbeda dibandingkan ketika belajar di sekolah lanjutan (Aqib, 2012). Karakteristik utama proses belajar pada perguruan tinggi yaitu kemandirian, baik itu dalam pelaksanaan kegiatan belajar dan pemilihan program studi, maupun dalam pengelolaan dirinya sebagai mahasiswa. Oleh sebab itu, pelaksanaan pelayanan bimbingan dan konseling di perguruan tinggi sangat penting guna menfasilitasi mahasiswa dalam menguasai keterampilan yang dibutuhkan sehingga mahasiswa sukses menjalani studi di perguruan tinggi.

Pelayanan bimbingan dan konseling memiliki berbagai jenis layanan, meliputi layanan orientasi, informasi, penguasaan konten, penempatan dan penyaluran, konseling individual, bimbingan kelompok, konseling kelompok, konsultasi, mediasi, dan advokasi (Prayitno, 2012; Nurihsan \& Sudianto, 2005). Jenis layanan tersebut dapat diklasifikasikan kedalam empat komponen arah pelayanan bimbingan dan konseling yaitu layanan dasar, peminatan dan perencanaan individual, responsif, dan dukungan sistem (Permendikbud, 2014). Fokus bidang pengembangan layanan bimbingan dan konseling di dunia pendidikan meliputi pribadi, sosial, belajar dan karir (Yusuf, \& Nurihsan, 2005; Tohirin, 2007; Permendikbud, 2014), selain itu, ada juga pengembangan bidang berkeluarga, berperkerjaan, berkewarganegaraan dan berkeagamaan (Prayitno \& Amti, 2009).

Pelayanan bimbingan dan konseling merupakan salah satu komponen pendukung yang dapat menunjang keberhasilan mahasiswa (Gallagher, 2013), karena pelaksanaan pelayanan bimbingan dan konseling memasuki segala aspek bidang kehidupan mahasiswa.

\section{KESIMPULAN}

Keterampilan belajar merupakan hal yang sangat penting. Salah satu keterampilan yang perlu dikuasai yaitu keterampilan mengingat (memory). Mahasiswa selalu menerima informasi-informasi yang berkaitan dengan keilmuan yang dipilihnya ketika di perguruan tinggi, maka teknik atau metode keterampilan mengingat (memory) perlu ditingkatkan, supaya segala informasi dapat diserap dengan semaksimal mungkin. Hasil penelitian menjelaskan bahwa keterampilan mengingat (memory) mahasiswa bimbingan dan konseling belum berkembang secara optimal. Layanan bimbingan dan konseling yang didukung dengan berbagai jenis layanan dan kegiatan pendukung mampu membantu mahasiswa dalam mengoptimalkan keterampilan mengingat (memory). Guru $\mathrm{BK} /$ Konselor profesional sangat berperan penting untuk terwujudnya kesuksesan dalam pelayanan bimbingan dan konseling. 


\section{DAFTAR PUSTAKA}

Aqib, Z. (2012). Ikbtisar Bimbingan dan Konseling di Sekolah. Bandung: Yrama Widya.

Brown, G. D. A., Neath, I., \& Chater, N. (2007). A ratio model of scale-invariant memory and identification. Psychological Review, 114(3), 539-576.

Choi, K. H., Buskey, W., \& Johnson, B. (2010). Evaluation of counseling outcomes at a university counseling center: The impact of clinically significant change on problem resolution and academic functioning. Journal of Counseling Psychology, 57(3), 297-303.

Davelaar, E. J., Goshen-Gottstein, Y. A. A., Haarmann, H. J., \& Usher, M. (2005). The demise of short-term memory revisited: Empirical and computational investigation of recency effects. Psychological Review, 112(1), 3-42.

Diamond, A. (2013). Executive functions. Annual Review of Psychology, 64, 135-168.

Djamarah, S. B. (2011). Psikologi Belajar. Jakarta: Rineka Cipta.

El Fiah, R. (2014). Urgensi layanan bimbingan dan konseling di perguruan tinggi (studi terhadap kebutuhan dan pencapaian tugas-tugas perkembangan mahasiswa untuk menyusun rancangan implementasi layanan bimbingan dan konseling di IAIN Raden Intan Lampung. Hasil Penelitian Individu. Lampung: LP2M IAIN Raden Intan Lampung.

Gallagher, R. P. (2013). National Survey of Counseling Center Directors. Alexandria, VA: International Association of Counseling Services.

Gibson, R. L \& Mitchel, M. H. (2008). Bimbingan dan Konseling. Terjemahan Yudi Santoso. 2011. Yogyakarta: Pustaka Pelajar.

Gie. T. L. (2002). Cara Belajar yang Efisien. Yogyakarta: Pusat Belajar Ilmu Berguna.

Hartley, M. T. (2011). Examining the relationships between resilience, mental health, and academic persistence in undergraduate college students. Journal of American College Health, 59(7), 596604.

Lee, D., Olson, E. A., Locke, B., Michelson, S. T., \& Odes, E. (2009). The effects of college counseling services on academic performance and retention. Journal of College Student Development, 50(3), 305-319.

Levine, M. (2002). A Mind at a Time. Simon and Schuster, Inc. Terjemahan Lina Jusuf. 2004. Jakarta: Gramedia Pustaka Utama.

Lubis, N. L. (2011). Memahami Dasar-dasar Konseling dalam Teori dan Praktik. Jakarta: Kencana.

Nurihsan, A. J. \& Sudianto, A. (2005). Manajemen Bimbingan dan Konseling di SMA. Jakarta: Grasindo.

Peraturan Menteri Pendidikan dan Kebudayaan Republik Indonesia. Nomor 111 Tahun 2014 tentang Bimbingan dan Konseling pada Pendidikan Dasar dan Pendidikan Menengah. Jakarta: Mendikbud.

Prayitno \& Amti, E. (2009). Dasar-dasar Bimbingan dan Konseling. Jakarta: Rineka Cipta. 
Prayitno. (2001). Panduan Kegiatan Pengawasan Bimbingan dan Konseling di Sekolah. Jakarta: Rineka Cipta.

Prayitno. (2012). Jenis Layanan dan Kegiatan Pendukung Konseling. Padang: UNP Press.

Prayitno. (2015). Konseling Integritas (Pola Konseling Indonesia). Yogyakarta: Paramitra Publising.

Sartika, M., \& Yandri, H. (2019). Pengaruh layanan bimbingan kelompok terhadap konformitas teman sebaya. Indonesian Journal of Counseling and Development, 1(1), 9-17.

Schwitzer, A. M. (2002). Using a chain-of-effects framework to meet institutional accountability demands. Journal of American College Health, 50(4), 183-186.

Sukardi, D. K. (2002). Pengantar Pelaksanaan Program Bimbingan dan Konseling di Sekolah. Jakarta: Rineka Cipta.

Tanjung, R. F. (2019). Answering the challenge of industrial revolution 4.0 through improved skills use of technology college. International Journal for Educational and Vocational Studies, 1(1), 1114.

Tanjung, R. F., Neviyarni, \& Firman. (2018a). Layanan informasi dalam peningkatan keterampilan belajar mahasiswa STKIP PGRI Sumatera Barat. Jurnal Penelitian Bimbingan dan Konseling, 3(2), 155-164.

Tanjung, R. F., Neviyarni, \& Firman. (2018b). Increasing skills reading students through guidance and counseling classical using Contextual Teaching and Learning (CTL) approach. International Journal of Research in Counseling and Education, 2(1), 8-14.

Tohirin. (2007). Bimbingan dan Konseling di Sekolah dan Madrasah. Jakarta: Raja Grafindo Persada.

Yusuf, S. \& Nurihsan, A. J. (2005). Landasan Bimbingan dan Konseling. Bandung: Rosda Karya. 